\title{
Methodology for surge pressure evaluation in a water injection system
}

\author{
P. Meliande ${ }^{1}$, E. Nascimento ${ }^{1}$, F. Mascarenhas ${ }^{2}$ \& D. Galgoul ${ }^{3}$ \\ ${ }^{1}$ Department of Civil Engineering, Fluminense Federal University, Brazil \\ ${ }^{2}$ Hydraulics Department, Federal University of Rio de Janeiro, Brazil \\ ${ }^{3}$ SHELL of Brazil
}

\begin{abstract}
Predicting transient effects, known as surge pressures, is of high importance for offshore industry. It involves detailed computer modeling that attempts to simulate the complex interaction between flowline and fluid in order to ensure efficient system integrity. Platform process operators normally raise concerns as to whether the water injection system is adequately designed in order to be protected against possible surge pressures during sudden valve closure. This report aims to evaluate the surge pressures in Bijupirá and Salema water injection systems due to valve closure, through a computer model simulation. Comparisons among the results from empirical formulations are discussed and supplementary analysis for the Salema system was performed in order to define the maximum volumetric flow rate that the design pressure was able to withstand. Maximum surge pressure values of 287.76 bar and 318.58 bar, obtained using empirical formulations in Salema and Bijupirá respectively, have surpassed the operating pressure design, while the computer model results have shown the highest surge pressure value to be 282 bar in the Salema system.
\end{abstract}

Keywords: transient analysis, surge pressure, water injection system, computational simulation.

\section{Introduction}

Techniques for assuring well production have been continuously implemented, and one of them is known as "water injection", which consists of applying water flow in wells to guarantee enough pressure to raise oil and gas flow. In a 
previous paper [1] the authors described a transient analysis performed on the Bijupirá and Salema oil fields located in Campos Basin, Brazil.

Equipment failures may be responsible for disturbances in subsea systems operation. The rapid closure of valves and unplanned pump operations are the most common reasons for transient problems, known as "water hammer" or "surge pressure". These effects may cause severe pressure fluctuations resulting in change of the steady-state operating conditions exposing the pipeline system to structural damage.

As stated by Miller [2], pressures fluctuations are the result of the interchange among the fluid kinetic energy, the fluid strain energy and the pipe wall. Such fluctuations are identified as oscillating, periodic, or pulsating disturbance waves, traveling at approximately sonic velocity, which are propagated to the fluid.

\subsection{Description of Bijupirá and Salema water injection systems}

Bijupirá and Salema were developed as subsea tiebacks to the FPSO, named FPSO Fluminense. The systems are comprised of subsea manifolds, flowlines, risers and jumpers with the capability of round trip pigging. The water injection system consists of two lines between the FPSO and the two subsea fields.

Bijupirá field is composed of six producer wells and four water injection wells, while Salema field comprises two producer wells and two water injection wells.

\subsection{Operating water injection system}

Most of the time the topside pressure remained between 220 and 230 bar. Due to this fact and in order to validate the simulation model, the turret pressure was assumed to be 230 bar.

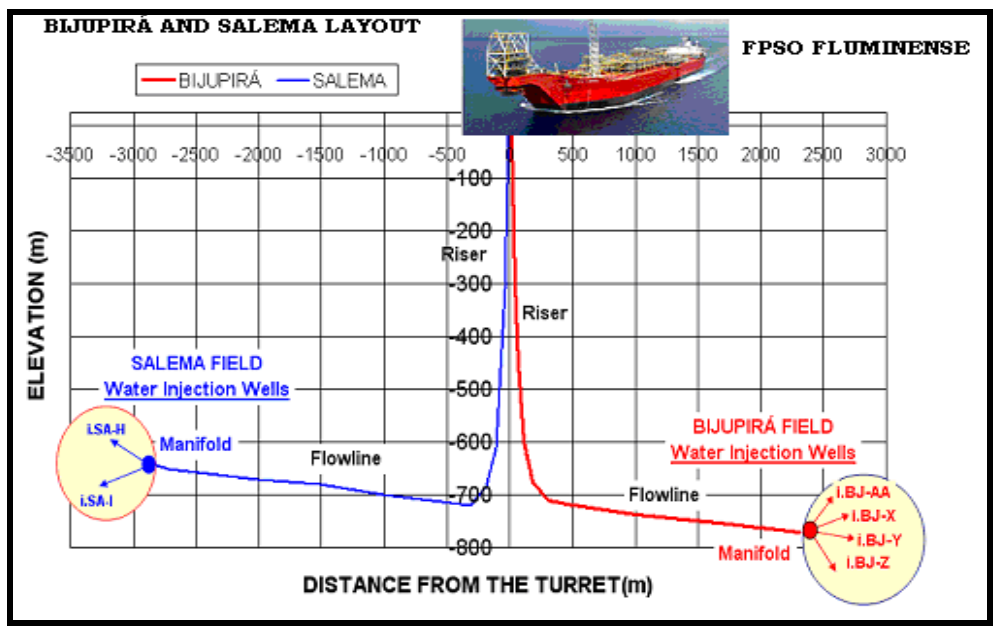

Figure 1: Bijupirá and Salema water injection system. 
All measured data are referred to piezometric pressure. Bijupirá and Salema fields are located respectively 770 and 640 meters of water depth. The total head pressure, considering the subsea level as reference datum, is equal to the topside pressure added to the external overpressure. The external overpressure will be then balanced with the internal pressure due to water transport. The value of 255 bar adopted for the operating pressure design, and defined in [3, 4], must be higher than the topside head in order to guarantee the operational system security. Figure 1 shows the injection line profiles from the FPSO turret to both fields.

Table 1 provides dimensions and properties of the flowlines, risers and jumpers, fundamental information to perform the transient analysis model.

Table 1: $\quad$ Pipeline dimensions and properties.

\begin{tabular}{|c|c|c|c|}
\hline \multirow{2}{*}{ LINE } & \multirow{2}{*}{ PARAMETER } & \multicolumn{2}{|c|}{ PRODUCTION FIELD } \\
\hline & & BIJUPIRÁ & SALEMA \\
\hline Flowline/Riser & ID (in) & 7.0 & 4.5 \\
\hline Flowline/Riser & Length (m) & 2876 & 3440 \\
\hline Flowline/Riser & Roughness (mm) & 0.005 & 0.005 \\
\hline Flowline/Riser & $\begin{array}{c}\text { Modulus of Elasticity } \\
\text { (PSI) }\end{array}$ & $2,000,403.00$ & $1,900,919.00$ \\
\hline Jumper Piping & ID (in) & 4.5 & 4.5 \\
\hline Jumper Piping & Length $(\mathrm{m})$ & 45 & 45 \\
\hline Jumper Piping & Roughness (mm) & 0.005 & 0.005 \\
\hline Jumper Piping & $\begin{array}{l}\text { Modulus of Elasticity } \\
\text { (PSI) }\end{array}$ & $29,000,000.00$ & $29,000,000.00$ \\
\hline
\end{tabular}

The average operating conditions of September 2006 was used to calibrate the simulation analysis model. Calibration process consists in one of the most important procedures in computational modeling, and it means compare the model results against the measured data by adjusting the model parameters in order to get the best approach between the model and the field data. In this sense, the pressure behavior and flow rates in the pipelines have been evaluated.

Table 2 shows the injection pressures, the water injection flow rates and the jumper velocities.

\section{Fluid transient methodology}

Based on the classical Fluid Mechanics literature [5], the first general formulation applied to fluid motion was performed by Euler. Through complex investigation associated to numerical analyses, differential equations such as the Navier-Stokes expressions have been developed to solve three directional fluid problems. The Saint-Venant equations are a simplification of the Navier-Stokes equations and describe how to solve numerically one directional fluid problem.

Bernoulli's Principle is explained in terms of the energy conservation law, and consists of a physical principle which states the increase in speed and decrease in pressure through the moving fluid. The phenomenon described by Bernoulli's Principle allows many applications, due to the fact that this Principle is expressed in terms of algebraic formulation, leading to suitable solutions. 
Table 2: $\quad$ Flow rates and injection pressures.

\begin{tabular}{|c|c|c|c|c|c|c|c|}
\hline \multirow{2}{*}{$\begin{array}{l}\text { OPERATING } \\
\text { DATA }\end{array}$} & \multirow{2}{*}{ UNIT } & \multicolumn{4}{|c|}{ BIJUPIRÁ FIELD } & \multicolumn{2}{|c|}{ SALEMA FIELD } \\
\hline & & I.BJ-AA & I.BJ-X & I.BJ-Y & I.BJ-Z & I.SA-H & I.SA-I \\
\hline \multirow{2}{*}{$\begin{array}{c}\text { Injection } \\
\text { pressure } \\
\text { (Piezometric } \\
\text { pressure) }\end{array}$} & Bar & 247 & 192 & 268 & 276 & 222 & 180 \\
\hline & (PSI) & 3,582 & 2,785 & 3,887 & 4,003 & 2,611 & 3,220 \\
\hline \multirow{2}{*}{$\begin{array}{c}\text { Flow rate to } \\
\text { well }\end{array}$} & $\mathrm{m}^{3} /$ day & 960 & 993 & 4,360 & 1,308 & 3,451 & 1,131 \\
\hline & Bbl/day & 6,040 & 6,246 & 27,425 & 8,228 & 21,706 & 7,113 \\
\hline $\begin{array}{l}\text { Jumper } \\
\text { diameter }\end{array}$ & Inch & 4.5 & 4.5 & 4.5 & 4.5 & 4.5 & 4.5 \\
\hline $\begin{array}{l}\text { Jumper } \\
\text { velocity }\end{array}$ & $\mathrm{m} / \mathrm{s}$ & 1.08 & 1.12 & 4.92 & 1.48 & 3.89 & 1.28 \\
\hline \multirow{2}{*}{$\begin{array}{c}\text { Flow rate to } \\
\text { field }\end{array}$} & $\mathrm{m}^{3} /$ day & \multicolumn{4}{|c|}{7,622} & \multicolumn{2}{|c|}{4,582} \\
\hline & Bbl/day & \multicolumn{4}{|c|}{47,940} & \multicolumn{2}{|c|}{28,819} \\
\hline $\begin{array}{l}\text { Flowline and } \\
\text { Riser } \\
\text { diameter }\end{array}$ & Inch & \multicolumn{4}{|c|}{7.0} & \multicolumn{2}{|c|}{4.5} \\
\hline $\begin{array}{l}\text { Flowline and } \\
\text { Riser velocity }\end{array}$ & $\mathrm{m} / \mathrm{s}$ & \multicolumn{4}{|c|}{3.55} & \multicolumn{2}{|c|}{5.17} \\
\hline
\end{tabular}

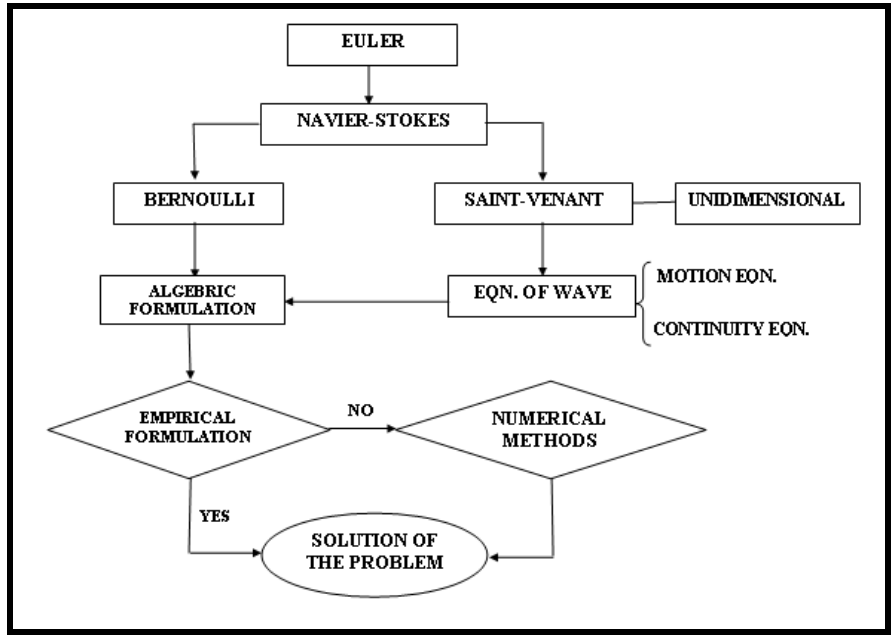

Figure 2: Description of the main hydraulics formulations.

The fluid transient or unsteady flow phenomenon comprises the equation of wave and may be represented mathematically through the combination of the Motion and Continuity differential equations. Nevertheless, in general, the solution of differential equations consists in a difficult task, and usually empirical formulations are employed to solve problems in spite of the conservative results obtained, which may compromise the cost-effective solutions. On the other hand, the advanced computational systems may contribute to provide efficient solutions, and may help to build simulation models which can identify the main transient factors, as pump start-up and 
changes in operational position of control valves, ensuring, consequently, the optimization of the pipeline system associated to cost-effective solutions.

The description of the hydraulics formulations, which explain mathematically the surge pressure phenomenon, may be identified from the fluxogram displayed in Figure 2.

\subsection{Equation of motion}

In accordance with Streeter and Wylie [6], the Equation of Motion is simpler to apply than the unsteady-momentum equation. This simplification may lead to an equation in terms of two dependent variables, instantaneous piezometric head and velocity, which should be taken into account in the Continuity Equation to provide solution of transient phenomenon. Loads are composed of pressure forces on the pipeline, the pipeline weight, and the frictional wall shear force resistant to the motion.

The Equation of Motion that considers the relationship between pressure and flow rate for an elastic system is shown in eqn (1), below.

$$
\frac{\partial v}{\partial t}+g \frac{\partial H}{\partial x}+\frac{f v|v|}{2 D}=0
$$

The third term in eqn (1), which represents the fluid friction force from the Darcy Equation, shows the absolute value sign of $v$ that has been introduced so that the fluid friction force is opposite to the direction of the velocity.

\subsection{Continuity equation}

The Continuity expression is a differential equation derived from the Conservation of mass Principle, which states mathematically that in a steady and one-directional flow the mass entering in a control volume is equal the mass leaving this volume, added to the change of mass rate.

The displacement of a fluid mass rate in a pipeline can be represented through the Continuity expression, since assumptions such as small deformations and linear elastic state of the pipe material are regarded. Therefore, the net mass inflow per unit time shall be equal the time rate of increase of mass within the space, as described in eqn (2).

$$
-\rho A v+\left(\rho A v+\frac{\partial}{\partial x}(\rho A v) d x\right)=\frac{\partial}{\partial x}(\rho A v) d x
$$

Considering the unitary time, the Continuity Equation may be written as eqn (3), in terms of a compressible and uniform transient flow.

$$
\frac{\partial v}{\partial x}+\frac{1}{\rho} \cdot \frac{\partial \rho}{\partial t}+\frac{1}{A} \cdot \frac{\partial A}{\partial t}=0
$$

Concepts of fluid volumetric Young Modulus and speed of pulse pressure, defined respectively in (4) and eqn (5), are fundamental to the complete Continuity expression, eqn (6). 


$$
\begin{array}{r}
\frac{d P}{\frac{d \rho}{\rho}}=K \\
c^{2}=\frac{K / \rho}{1+\frac{K \cdot D \cdot \phi}{t \cdot E}} \\
\frac{\partial H}{\partial t}+\frac{c^{2}}{A \cdot g} \cdot \frac{\partial Q}{\partial x}=0
\end{array}
$$

\subsection{Classification of valve closure time}

During a transient phenomenon, the kinetic energy of a flow is converted to pressure energy due to a decrease in flow velocity. Considering a sudden closure of a valve and the resulting pressure wave that propagates up and down the pipe, the maximum pressure change will occur at the location where the disturbance is generated, and the valve-closure time is an essential parameter to the classification of the transient phenomenon.

Pressure changes due to disturbances are classified into three distinct types depending upon the relationship between the time taken to change the flow velocity completely, $\mathrm{T}$, which corresponds to the valve closure time, and the pipeline period, $2 \mathrm{~L} / \mathrm{c}$, which consists of the time for a pressure wave propagating from a point of reflection and return. RAPID EVENT

$$
T \leq \frac{2 L}{c}
$$

A rapid event is one in which the change in flow occurs in less than one pipeline period. The pipeline should be simulated as an elastic pipe model.

SLOW EVENT

$$
\frac{2 L}{c} \leq T \leq 500 \frac{2 L}{c}
$$

A slow event is one in which the change in flow occurs between 1 and 500 pipeline periods. For slow events the maximum pressure change is proportional to the full pressure change predicted for a rapid event. In the case of flow changes that occur between 2 and 3 pipeline periods, the pressure reduction is negligible. For transient events greater than $10 \times(2 \mathrm{~L} / \mathrm{c})$ it may be appropriate to assume rigid column behavior and use the rigid pipe model.

VERY SLOW EVENT

$$
T \leq 500 \frac{2 L}{c}
$$

A very slow event is one in which the change in flow occurs in a time greater than 500 pipeline periods. For these events the magnitude of the maximum pressure change is proportional to the rate of change in flow velocity and independent of wave speed. Consideration should be given to the use of rigid pipe model. 


\subsection{Empirical formulation}

In order to define the magnitude of surge pressure and determine the increment of resultant pressure obtained during an event, empirical formulations are usually applied. Although these formulations have been written based on assumed simplifications, they are widely employed.

Due to the fact that the pipeline dimensions are much greater than the jumper dimensions, the evaluation of surge pressures through empirical formulations may be regarded as linear within the elastic domain.

Empirical formulations highlighted in this report are displayed as follows.

\subsubsection{Joukovski}

Joukovski formulation was the first attempt to associate surge pressure with a sudden change in velocity and is written as showed in eqn (10):

$$
h_{a}=\frac{c}{g} \cdot \Delta v
$$

\subsubsection{Allievi}

Years Later, Allievi extended the Joukovski formulation by including pressure changes due to slow valve closure. The constant $\mathrm{C}$ in Allievi formulation, eqn (11), shows the proportionality among pressure head, valve closure time, fluid velocity and flowline length. The Surge Pressure is given by eqn (12).

$$
\begin{gathered}
C=\frac{L \cdot v}{g \cdot H \cdot T} \\
h_{a}=\frac{H}{2} \cdot\left(C^{2}+C \cdot \sqrt{4+C^{2}}\right)
\end{gathered}
$$

\subsubsection{Michaud, Vensano and Warren}

Michaud, Vensano and Warren formulation, shown in eqn (13), expresses the surge pressure correlated to the valve closure time. The similarity with the Joukovski formulation can be seen by replacing in eqn (10) the pipeline period term, 2.L/c.

$$
h_{a}=\frac{2 \cdot L \cdot v}{g \cdot T}
$$

\subsubsection{De Sparre}

According to the theoretical studies of De Sparre, the maximum overpressure due to a valve closure time will be less than the value obtained by Michaud's formulation. De Sparre's surge pressure formulation is expressed by eqn (14).

$$
h_{a}=\frac{2 \cdot L \cdot v}{g \cdot T} \cdot \frac{1}{2 \cdot\left[1-\frac{L \cdot v}{2 \cdot g \cdot T \cdot H}\right]}
$$


As can be seen, this expression is similar to eqn (13), unless the second term which leads to a decrease of the surge pressure result.

\section{Computer simulation model}

The conceptual model for Bijupirá and Salema systems has been performed according to the available field data and the basic assumptions on transient analysis. The Characteristics Method [6] is applied in the computer model in order to solve the transient phenomena represented by the so called wave equation. Water injection systems have been modeled considering the pipeline as an elastic element and the jumper as a rigid element.

The water injection well systems are comprised of one choke used to control the injection rate, and two valves - wing and a master valve - to close the wells. It was considered a valve closure time of 8 seconds.

Figure 3 shows a scheme that represents the network of Bijupirá and Salema.

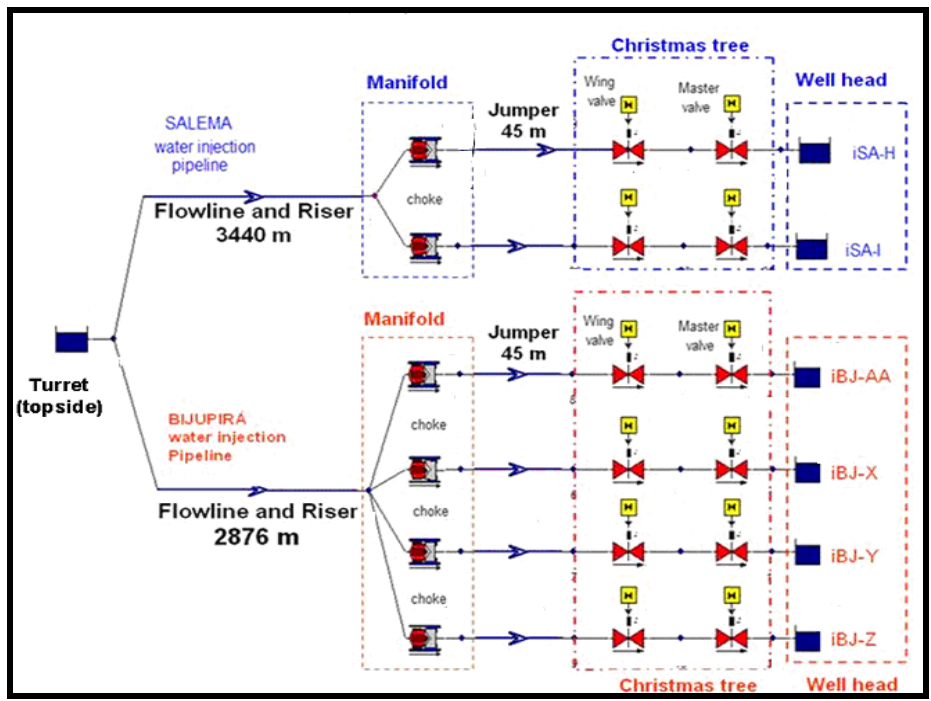

Figure 3: $\quad$ Computer simulation model.

\section{Results}

Results from computer simulation model and empirical formulations are presented and discussed in this section.

\subsection{Empirical formulations}

Table 3 presents the surge pressure increments from each empirical formulation described in section 2.4 and the resultant surge pressures, considering the greatest injection pressure at Bijupirá (276 bar) and Salema (222 bar) wells. 
Table 3: $\quad$ Surge pressure results from empirical formulations.

\begin{tabular}{|l|c|c|c|c|}
\hline \multirow{2}{*}{ FORMULATION } & \multicolumn{2}{|c|}{ Surge Pressure increment } & Max. Surge Pressure \\
\cline { 2 - 5 } & Salema & Bijupirá & Salema & Bijupirá \\
\cline { 2 - 5 } & ha (bar) & ha (bar) & $\mathbf{P}$ (Bar) & P (Bar) \\
\hline Joukovski & 65.76 & 42.58 & 287.76 & 318.58 \\
\hline Warren, Michauld, Vensano & 65.76 & 42.58 & 287.76 & 318.58 \\
\hline De Sparre & 35.51 & 22.14 & 257.51 & 298.14 \\
\hline Allievi & 35.40 & 22.33 & 257.40 & 298.33 \\
\hline
\end{tabular}

\subsection{Surge pressure in computer model analyses}

The first analyzed scenario was related to the closure of one valve in Salema, which led to a surge pressure of 261 bar. When two wells were simultaneously closed the surge pressure reached the highest value of 282 bar.

Related to Bijupirá scenarios, the simulation of closing simultaneously one, two and three wells led to the surge pressures of 246 bar, 253 bar and 259 bar, respectively. When all wells were closed the surge pressure reached 265 bar, which is still less than the pressure at Salema when all valves were closed.

When all valves in both systems are closed at the same time the simulation signalized surge pressures of 282 and 265 bar, respectively, at Salema and Bijupirá fields, indicating that no influence of the surge pressure from one set of wells upon the other occurred.

The maximum value of the surge pressure reached 282 bar, surpassing the expected design pressure of 255 bar. When this scenario often happens, damage consequences as resonance phenomenon may lead to fatigue process of the pipeline system.

\subsection{Comparison between computer model and empirical expressions results}

The empirical formulation results above showed that the highest surge pressure in Bijupirá (318.58 bar) was greater than that obtained in Salema (287.76 bar). The main assumption for this fact might be clarified due to the fact that empirical formulations take into account the pressure head on the turret disregarding head losses throughout the pipeline and riser.

On the other hand, the simulation model has shown that the highest pressure value of 282 bar has occurred in Salema system. This may be explained by the Joukovski and Michaud formulations, once the flow velocity in Salema system $(5.17 \mathrm{~m} / \mathrm{s})$ is higher than the velocity in Bijupirá $(3.55 \mathrm{~m} / \mathrm{s})$. Comparisons between both analyses are graphically displayed in Figure 4 .

In graphic above, the surge pressures obtained from computer simulation model and the corresponding pressures for each empirical formulation are shown. Results from computer simulation analyses and empirical formulations pointed surge pressure values higher than the operating pressure design, established for the water injection systems.

\subsection{Supplementary analyses}

Taking advantage of computational resources, supplementary analyses were performed to the water injection system of Salema aiming at determine injection 


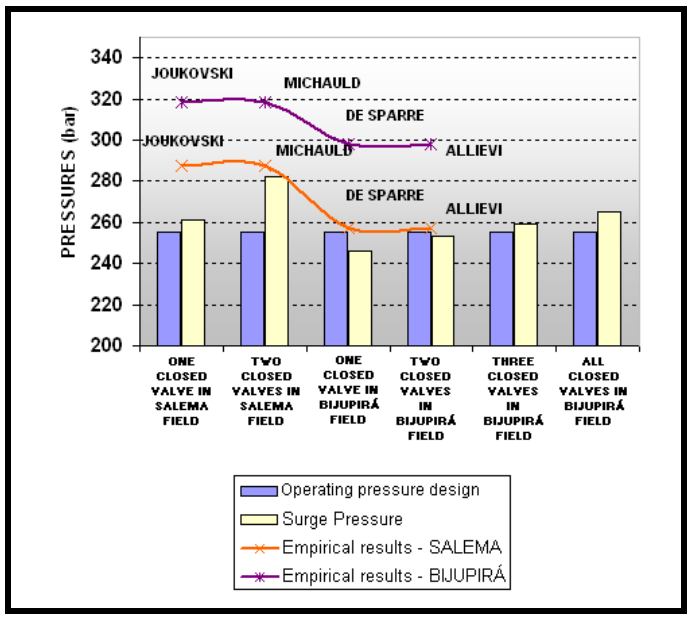

Figure 4: $\quad$ Pressure results for Salema and Bijupirá water injection systems.

flow rates which would allow the increase in oil production level without causing damage to the system. Based on flow rate and pressure data, the surge pressure reached 264 bar when the valve i.SA-H was suddenly closed.

Maintaining the hydraulic transient pressure below the design pressure of 255 bar, following oil flow rates were achieved:

$\rightarrow$ For the topside pressure of 230 bar the allowable flow rate was 12,000 bbl/day;

$\rightarrow$ For 240 bar at the turret the allowable flow rate dropped to 7,000 bbl/day;

$\rightarrow$ For the turret pressure of 217 bar, the flow rate was 20,000 bbl/day;

$\rightarrow$ For the turret pressure of 210 bar, the obtained flow rate was $25,000 \mathrm{bbl} /$ day.

\section{Conclusions}

Computer simulation is a powerful tool widely used in many fields of research and leads to more realistic and accurate approach of the transient phenomena. One of its main advantages compared to empirical formulations consists in the fact that through simulations models the relationship among pressures at the turret and injection flow rates are clearly shown, while conventional techniques involving empirical formulations just determine the surge pressure magnitudes. Simulation models applied to Bijupirá and Salema water injection systems were consistent with the operational data. Relationship between injection' effectiveness and oil production rates was discussed.

Although special routines have been implemented in computer programs the validation of the obtained results still remains a challenge for future researches. 


\section{Nomenclature}

$\mathrm{h}_{\mathrm{a}}=$ Magnitude of the head rise (m)

$\mathrm{H}=$ Pressure head $(\mathrm{m})$

$v=$ Flow velocity $(\mathrm{m} / \mathrm{s})$

$\mathrm{c}=$ Wave speed $(\mathrm{m} / \mathrm{s})$

$\mathrm{g}=$ Gravity acceleration $\left(\mathrm{m} / \mathrm{s}^{2}\right)$

$\rho=$ Fluid density $\left(\mathrm{kg} / \mathrm{m}^{3}\right)$

$\mathrm{k}=$ Bulk modulus the liquid $\left(\mathrm{N} / \mathrm{m}^{2}\right)$
$\Phi=$ Pipe restraint factor

$\mathrm{t}=$ Pipe wall thickness $(\mathrm{m})$

$\mathrm{E}=$ Young's Modulus $\left(\mathrm{N} / \mathrm{m}^{2}\right)$

$\mathrm{T}=$ Pipeline period $(\mathrm{sec})$

$\mathrm{L}=$ Pipeline length $(\mathrm{m})$ FPSO = Floating, Production, Storage and Offloading

\section{Acknowledgements}

The authors would like to express their thankfulness to the WIT Conference members for the evaluation of this technical report and are grateful for the collaboration of SHELL of Brazil for allowing the publication of this paper.

\section{References}

[1] Meliande, P., Nascimento, E.A., Dandoulakis, J.P., Massa, A.L.L., Surge pressure analysis for Bijupirá and Salema water injection system, OTC19365, Offshore Technology Conference, Houston, Texas, 5-8 May, 2008.

[2] Miller, D.S., Internal flow systems, 2. ${ }^{\text {nd }}$ edition, BHRA, 1990.

[3] DNV OS F 101, Submarine Pipeline Systems, October, 2007.

[4] API RP 17B, Recommended Practice for Flexible Pipe, 2002.

[5] Azevedo Netto, J.M., Fernandez, M.F, Araujo, R., Eji Ito, A., Hydraulics

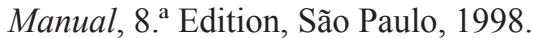

[6] Streeter, V.L., Wylie, E.B., Hydraulic transients, McGraw-Hill, New York, 1967.

[7] Vuuren, S.J., Theoretical Overview of Surge Analyses, University of Pretoria, 2001.

[8] FLOWMASTER Manual, version 7.4.1. England, 2005. 